Article

\title{
Climate Change Adaptation, Food Security, and Attitudes toward Risk among Smallholder Coffee Farmers in Nicaragua
}

\author{
Aniseh S. Bro
}

Sustainable Development Department, Living Learning Center, Appalachian State University, Boone, NC 28608, USA; broas@appstate.edu

Received: 7 June 2020; Accepted: 18 August 2020; Published: 26 August 2020

check for updates

\begin{abstract}
Farmers' livelihoods are uniquely vulnerable to climate change, and taking adaptive measures to changing environmental conditions constitutes one of the most important pathways for protecting them. Their willingness and capacity to adopt improved practices and technologies, their cognitive and behavioural preferences, and the institutional response mechanisms will go a long way in determining their success in their adaptation to climate change. This study presents results of an analysis of the vulnerabilities of smallholder coffee producers in Nicaragua to climate change. I use descriptive analyses and experimental risk games to evaluate the preferences and attitudes of coffee producers in the context of their adaptation to climate change. I show that food insecure households are more risk-averse than food-secure households and that much work is needed in the sector to ensure equity and improve institutional capacity. For households in chronic poverty, conventional risk management strategies simply may not be enough. Institutional arrangements must be put in place to enable coffee-growing households to engage in practices that result in improved capacity for climate change adaptation.
\end{abstract}

Keywords: Nicaragua; food security; climate change; coffee; adaptation

\section{Introduction}

The earth's climate is changing rapidly. Climate scientists forecast higher temperatures and significant changes in precipitation patterns that in turn will alter crop suitability and land use in many agricultural regions of the world [1]. Farmers will see changes in their agricultural productivity, their farm income, and their food security [2,3]. Poor, rural households in low-income countries that depend directly on natural resources for income generation and their own food consumption will be burdened disproportionately by the adverse impacts of climate change. Because their livelihoods are so closely tied to the local agroecology, they will be among the most vulnerable to sudden impacts like droughts, floods, famine, wildfires, epidemics, and potentially violent conflict [4]; as well as to the long-term vulnerabilities that result from recurring events over time. For farmers, especially vulnerable smallholder farmers, taking measures to adapt to climate change will be one of the most important paths for protecting their livelihoods. Their willingness and capacity to adopt improved practices and technologies, their cognitive and behavioural preferences, and the institutional response mechanisms in place will go a long way in determining their success in their adaptation to climate change.

Socioecological vulnerability to climate change, as defined by the Intergovernmental Panel on Climate Change (IPCC) [5], is the degree to which a system is susceptible to adverse effects. In the context of the current study, vulnerability is the susceptibility of the coffee sector (both its social and ecological components) to changes in the suitability of coffee production due to changing environmental conditions. Vulnerability hinges on the sensitivity of coffee to changes in climate, the adaptive capacity 
of the ecosystem, and the degree to which coffee farms are exposed to climate hazards. In light of this definition, I define vulnerable populations as those who are embedded within the vulnerable system and whose livelihoods are tied to it and depend on it. Vulnerable populations need to adapt to increasingly severe impacts from climate change. Adaptation is the change that happens in response to observed or expected climatic stimuli [5], which can mean adapting by mitigating the risks from future threats or by taking advantage from opportunities associated with environmental change, and it involves a set of activities, actions, decisions, and attitudes [6] that shape how individuals adapt to these changes. As a result of adaptation, individuals should experience improved wellbeing and reduced exposure to the environmental threat.

The capacity of individuals to engage in the activities that lead to adaptation depends on the incentives that they have on their cognitive and behavioral preferences, and on their perceptions of the level of threat associated with changing environmental conditions [7]. Even when farmers are willing improve their adaptive capacity by adopting (potentially risky) new technologies and practices, they may face binding constraints that will make it hard or impossible to do so, such as high transaction costs, poor physical infrastructure, lack of access to inputs and seeds, and low levels of institutional support and capacity [8]. For example, although crop diversification can help to decrease farmer vulnerability to climate change impacts, Bradshaw et al. [9] find that farmers increasingly specialize their production systems when faced with economic factors such as high start-up costs and economies of scale.

Anticipating climate change adaptation is challenging, since climate change is a complex phenomenon driven by processes that are not spatially proximate and riddled with uncertainty about slow and sudden onset impacts with interactions across time and space. Predicting human behaviour has always been hard, and adaptation is especially hard because it requires that we predict future behaviour under changing conditions, combining social and cultural dimensions with biophysical, economic, and policy dimensions [10]. Adaptation occurs after an individual has undergone a cognitive process, which is influenced by a complex range of interacting factors such as individuals' beliefs, the social norms that shape their lives, their exposure and experience with environmental impacts, and their attitudes and cognitive preferences. These decisions are further influenced by the challenges that uncertainty and psychological distance place on perception, and the profoundly social nature of human action [11].

Institutional capacity is also needed to produce long-term strategic interventions that facilitate networking, information sharing, and the creation of safety nets. The formation of agricultural cooperatives, for example, has been successful in helping smallholder farmers to overcome barriers associated with access to inputs, financial services and market participation, through the dissemination of inputs, loans, and training opportunities [12], and have been successful in promoting the use of sustainable production practices [13]. In a study of cooperatives in Nicaragua, however, Bacon [14] finds that coffee cooperatives in the country have struggled with issues of trust, transparency, lack of support, and corruption. In another study of the correlations between cooperative membership and food security in Nicaragua, Bacon et al. [15] found that even though cooperatives developed interventions to help households cope with unexpected events, these interventions were not successful in helping with the food security of households. Community-based natural resource management strategies can also enhance the adaptive capacity of farmers by creating social networks that are essential for coping with extreme events and by retaining the resilience of ecological systems [16].

Among crops that will see a shift in suitability, coffee has received much attention, given its importance in the global market and the large number of smallholder producers worldwide that depend on it as a main source of income [17-20]. Coffee has long been known as a commodity product with a large footprint in poor countries in the tropics, and as a leading source of economic growth for many of them. At a global scale, it is considered one of the most traded commodities [20]. With climate change, coffee regions around the world will be characterized by seasons marked with higher temperatures, erratic and severe rainy seasons, and longer and more extreme periods of drought [21,22]. All of these 
changes will impact coffee production and the farmers that depend on it, as the coffee tree is vulnerable to droughts, excessive rain, and temperature extremes [23].

This study presents results of an analysis of the vulnerabilities of smallholder coffee producers in Nicaragua to climate change, and while recognizing that climate change may result in the displacement of people [24], in this study I focus on the immediate behavioral responses that farmers take in response to climate change impacts. Although this study is conducted in Nicaragua, the relevance of the results is applicable to many of the coffee-growing regions of the world that are currently experiencing increased vulnerability due to climate change. In East Africa (including Ethiopia, Uganda, Kenya, Rwanda, and Burundi), farmers have been experiencing earlier and unexpected flowering of coffee trees [25] and increased pests due to changes in seasonal pattern [26], as well as drier and hotter seasons, and more severe and variable rainfall patterns [25,27]. Similarly, coffee regions in Latin America are also experiencing loss of coffee production suitability due to climate change [28-30]. In this study, I use descriptive analyses and experimental economic methods-risk games-to evaluate the preferences, attitudes, and capacities of coffee producers in Nicaragua to assess their capacity for climate change adaptation. I show that food insecure households are more risk averse than those that are not food insecure, and that much improvement is needed in the sector to ensure equity and improved institutional capacity.

The remainder of this paper is organized as follows: I begin by providing an overview of the coffee sector in Nicaragua and how it is expected to change as a result of climate change, followed by a brief literature review of farmers' behaviours under conditions of scarcity. I then describe the study site and data collection methodology followed by an explanation of the economic games that are used to assess attitudes towards risk. I continue by presenting the results followed by a section with a discussion about the main findings. I conclude by describing some of the policy implications and providing recommendations for future research.

\section{Background}

\subsection{Coffee in Nicaragua}

Nicaragua is one of the poorest countries in Latin America with more than $42 \%$ of the population living in poverty and most in rural areas [31]. Coffee in Nicaragua is by far the most important crop in the economy, and it is the highest source of agricultural export revenues in the country. There are more than 48,000 coffee producers in Nicaragua, producing mostly Arabica coffee, the majority of them farm on plots of less than 3.5 hectares [32]. Nicaragua, as much of Central America, has experienced devastating losses due coffee leaf rust outbreaks, a particularly large one in 2011 left food insecure households even more vulnerable to ongoing environmental impacts, such as droughts [15].

Climate change is expected to affect a large proportion of coffee growing areas in Nicaragua, which will be marked by greater seasonal variability in temperatures and precipitation. Current coffee areas of Nicaragua will see up to $60 \%$ decrease of area suitable for coffee production [2]. For vulnerable food insecure households who are at the mercy of market and climatic fluctuations, finding a pathway to resilience and adaptation is urgent and the only way forward. Earlier research by Laderach et al. [2] has identified ways for coffee farmers to improve their income potential; they include: (a) the adoption of certain coffee production practices that will improve their adaptive capacity to climate change, (b) moving from coffee production altogether to a different high value crop, such as cocoa, which can help maintain or increase their current income, or (c) dropping out of agricultural production and finding non-farm employment (perhaps still related to agriculture).

The search for adaptation strategies within agricultural systems has mostly focused on technical and productivity interventions-such as the development of forecasting systems, and changes in the location of production [33]. Less common, however, is the recognition that farm management practices can significantly contribute to improved adaptation by producers through, for example, the adoption of integrated pest management and through the incorporation of shade into coffee 
farms. Evidence has shown that agro-ecological management practices can significantly improve resilience to climate change [33,34]. For example, in a study of 880 paired experimental plots in Nicaragua, Holt-Gimenez [35] found that after Hurricane Mitch hit the country in 1998, plots that had been following Sustainable Land Management (SLM) practices were able to recover more quickly than plots conventionally managed. Given the positive relationship between hurricanes and climate change [36], SLM could be an important strategy for farmers wishing to become more resilient to their impacts, and the impacts of other similar storm events. SLM includes a variety of soil conservation, agro-ecological, and agroforestry practices that generally avoid external inputs. The study finds that farms following SLM practices had more topsoil, higher field moisture measures, more vegetation within the system and lower economic losses than the conventional plots. Not only do we need to know if producers are able to adopt practices that help in their adaptation but also if they are willing to do so.

Farmers may have attitudes and preferences that prevent them from taking steps that will ensure the long-term viability of their livelihoods [37]. Among these, their attitudes toward taking risk taking are paramount. Poor households are often highly risk averse-and for good reason: they can be one exogenous shock (e.g., climate shock or market fluctuation) away from losing most or all of their assets [38]. With each sequential shock, compounded upon previous shocks and vulnerabilities, these households are at risk of spiraling downward and falling into a poverty trap from which they cannot easily emerge [39].

The question of uncertainty and risk in the adoption of new agricultural technologies has been explored extensively in the literature. Risk aversion - argued to be a direct result of socio-economic conditions [40] - has often been considered a major factor in reducing the rate of adoption [41-45]. Studies have found that risk behaviour is associated with crop diversification, but have found differences on the direction of this relationship. While Ayenew et al. [46] find that risk behaviour is positively associated with on-farm diversification in Ethiopia (i.e., farmers who are willing to take risks are more likely to also incorporate additional crops into their farms), Lawin and Tamini [47] found that smallholder farmers with more land tend to diversify their crop production as a form of risk mitigation.

In Peru, Engle-Warnick et al. [48] find that risk-averse farmers are less likely to adopt new, higher yielding, potato varieties. In another study of risk attitudes and preferences of agricultural households in Ethiopia [40], conclude that large households with a higher proportion of elderly and young children showed higher risk aversion than other households, while Cardenas and Carpenter [49], in a study of risk attitudes across multiple countries in Latin America, find that women are more risk averse than men and that older individuals are more willing to take risks than younger ones. The gender differences could be explained by a number of reasons. Men and women respond to shocks differently, and their vulnerability to these shocks is also different [50]. Women, in addition to the restrictions that they face due to cultural norms (such as not being able to own land, or their responsibility as homemakers and primary caregivers of children and the elderly), often have lower access to extension services and fertile land [14,51]. Understanding attitudes towards risk, and differences in attitudes between men and women, can provide important insights into why and when farmers may choose to engage in practices that lead to adaptation.

Much of the literature about risk aversion has been motivated by the proposition that poverty can be explained by risk aversion, or that people remain poor due to preferences and attitudes that are incompatible with growth [52], or that people are too risk-averse to take the opportunities and chances needed to increase their resources and improve their wellbeing [53]. Yet, in an extensive review of the experimental literature, Cardenas and Carpenter [49] find that the literature does not support this proposition; in fact, they find very little evidence that poor people in developing countries are more risk averse than others.

It is not yet clear if there is a universal relationship between income and risk attitudes. On the one hand, some studies have found that there is a relationship between income and risk aversion, mainly, that lower income households are more risk averse than higher income households [38,54-56]. On the 
other hand, another set of similar studies have been unable to show this relationship, and do not find that poor households are more risk averse than other households $[57,58]$.

A related and important area of research also studies how scarcity affects behaviour and attitudes. In a study of behaviour under scarcity, Haushofer and Fehr [59] state that material scarcity detrimentally changes people's allocation of their attention, affecting their behaviour and decision-making. Agarwal [60] finds that households facing the most financial constraints would steal wood from a protected forest, and risked getting caught and fined, in order to provide cooking fuel for their homes, exhibiting riskier behaviour. While Levy et al. [61] find that a person, who on average tends to be risk-tolerant (willing to take risks) when they are not deprived of food, will shift towards high risk aversion, when they experience hunger and deprivation.

This study contributes to this body of research by examining the risk perceptions of coffee farmers in Nicaragua who are suffering from severe food insecurity. I use experimental games to measure risk aversion, and use the results of these experiments together with a series of descriptive analyses to study the capacities and incentives of coffee producers for climate change adaptation. By centering my attention on the livelihoods of coffee worker who are experiencing unprecedented impacts associated with changing environmental conditions, I also avoid the common mistake of shifting narratives away from the people when talking about the biodiversity crisis associated with climate change [62].

\subsection{Description of the Study Site and Sample}

This study was conducted in the department of Matagalpa in northern Nicaragua between June and July 2015. A map of the study area is presented in Figure 1. The department of Matagalpa is divided into 13 municipalities that contain one or more communities, the smallest administrative unit. A sample of 236 households was selected using a two-stage stratified random selection strategy. First, communities in Matagalpa were stratified by level of vulnerability to climate change. Vulnerability was determined by the average elevation in which the community was located. Higher elevation (above $1000 \mathrm{~m}$ above sea level) had a lower vulnerability index than those at lower elevations, as households in higher elevations will be less affected by increased temperatures. In this first stage, a random sample of communities was selected based on their vulnerability index. In the second stage, households in each of the selected communities were drawn from a census listing of coffee producers in the region. While I conducted the descriptive analyses on the larger sample, I drew a subsample of 88 households to participate in the risk experiment (due to budget constraints, it was not possible to conduct the experiments with 236 households). I compared the two groups (the 88 participants in the games versus the 148 non-participants) across a set of key demographic and farm characteristics and found no statistically significant difference between these two groups, helping to ensure that the subsample introduces no measurable bias to the results from the risk experiment analysis. The households surveyed in this study form part of a project lead by the International Center for Tropical Agriculture (CIAT), which focused on understanding how the food security and livelihoods of coffee-producing households will be impacted under different future climate scenarios in all of the coffee-producing regions of Nicaragua. From this overall sample, I selected a random subsample of communities in Matagalpa and surveyed all of the households selected through the sampling strategy developed by CIAT and described above.

After eliminating households for which data were missing or incomplete, I reduced the dataset for this analysis to 221 households for the descriptive analysis, and 82 for the risk experiments. Nine out of 13 municipalities are represented in the data; I did not sample from the remaining municipalities because they do not produce coffee. 


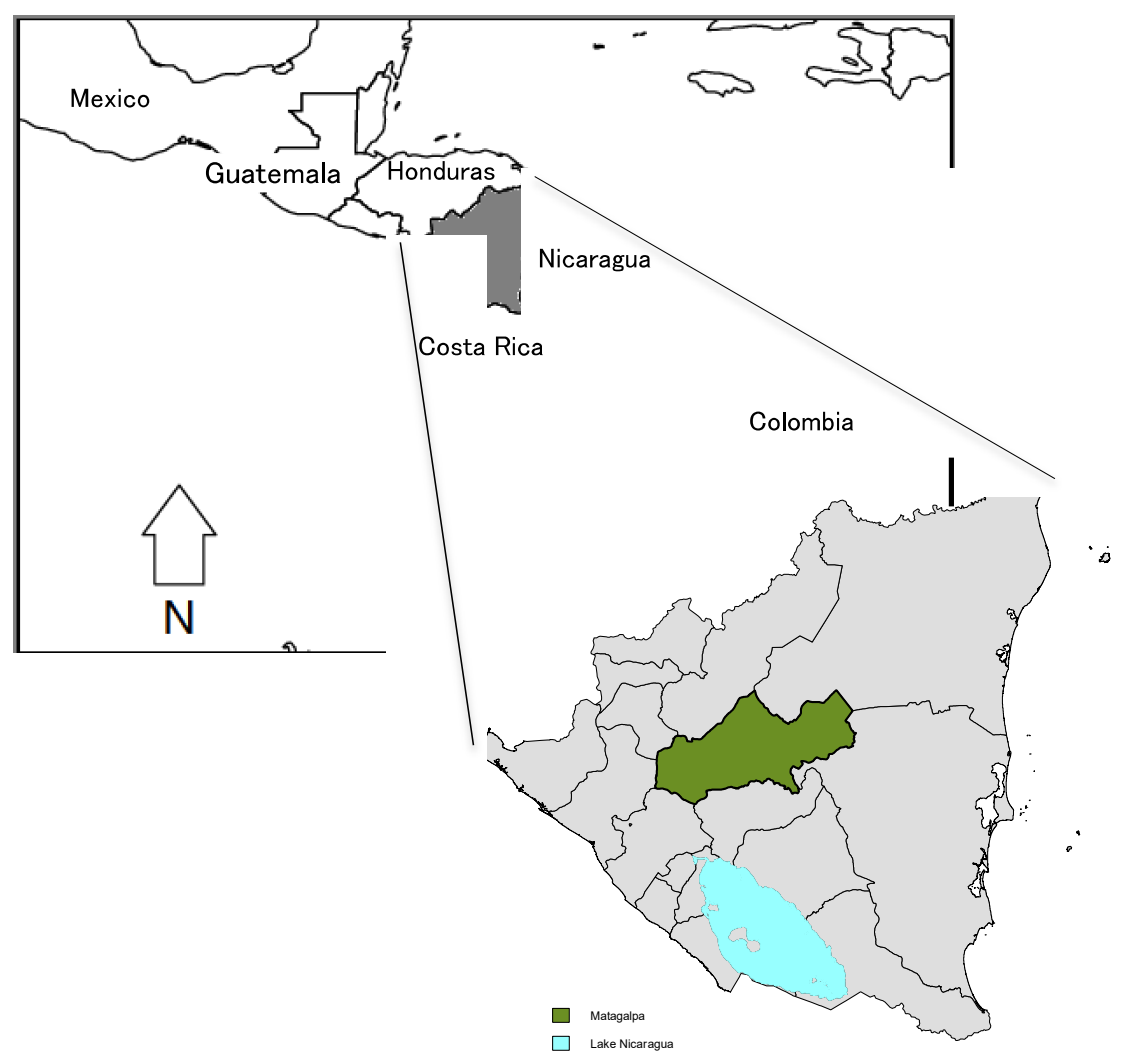

Figure 1. Map of the study area.

Producer information was collected on, among other things, demographic and socio-economic characteristics, agricultural production, and experiences with economic and climatic shocks. Table 1 summarizes some of the characteristics of the producers in the sample. The average age of the respondents is 46 years with an average of 3.8 years of formal education completed. The mean area under production is 4.85 hectares and the mean annual coffee production is 9.7 quintales $(446.2 \mathrm{~kg})$ of wet parchment per hectare (wet parchment is a state of the coffee in its transformation from cherry to bean). After harvesting, the freshly harvested cherries are passed through a pulping machine to separate the skin and pulp from the bean. After depulping, the bean is transported to water filled tanks for fermentation, where they remain from 12 to $48 \mathrm{~h}$. When fermentation is complete, the beans are rinsed and are ready for drying. Coffee at this stage of the wet milling process is known as wet parchment. The Green Bean Equivalent (GBE) of 9.7 quintales of wet parchment to green bean is $179.4 \mathrm{~kg}$ ). Forty-six percent of the sample are members of a coffee cooperative and $65 \%$ are male-headed households.

Table 1. Sample Characteristics.

\begin{tabular}{ccc}
\hline Variable & \multicolumn{2}{c}{ Means (\% Where Noted) } \\
\hline Male & $65.4 \%$ & $(15.28)$ \\
Age & 46.4 & $(2.12)$ \\
Household Size & 5.4 & $(3.48)$ \\
Years of Education & 3.8 & $(12.48)$ \\
Years in Coffee & 16.5 & $(875.11)$ \\
Total Coffee Income (USD) per ha & 821.8 & $(7377.11)$ \\
Total income (USD) & 5648.3 & $(5.38)$ \\
Coffee farm size (ha) & 4.8 & $(120.59)$ \\
Total Coffee Production (quintales *) per ha & 9.7 & \\
Cooperative membership & $45.5 \%$ & \\
\hline
\end{tabular}

${ }^{*}$ Quintal $=46 \mathrm{~kg}$; Standard deviations are presented in parentheses. 
In addition to these primary data, I use data for two variables provided by the International Center for Tropical Agriculture (CIAT): (1) an indicator of household vulnerability to climate change which takes into consideration predictions of temperature changes in 2020 and 2050 in combination with the elevation at which the household is located; and (2) an indicator of household food insecurity that is based on whether households have had to compromise the quality and quantity of the food consumed by the adults and the children in the household.

\subsection{Description of the Framed Field Experiments}

Economic experiments were used to measure attitudes towards risk by observing the behaviour of farmers in a set of one-period lottery games with real pay-offs. The experiments were designed with gains-only payoffs; given the income constraints of farmers who participated in these experiments, I chose to not have games in which the worst possible loss exceeds their current cash holdings.

Following Binswager's design [63], I conducted one lottery choice experiment intended to assess participants' attitudes towards risk. In the game, the participant was shown a lottery choice on a laminated card with six different possible binary payoffs and asked to pick one to play. To avoid problems that might arise if participants had a hard time understanding probabilistic outcomes, I used a simple 50/50 chance scenario with the producers.

The risk experiment was framed as follows: I told farmers that due to uncertain weather, the yield from the upcoming coffee harvest would be affected in such a way that there was an equal likelihood of crop failure and crop success, and in anticipation to these two possible outcomes, farmers had the opportunity to adopt one of six different strategies (or choices).

I followed Holt and Laurie [64] to determine the parameters of the experiment; they suggest that a good starting point to determine the payoff levels is to use the daily pay rate of a farmer in the region where the study will be conducted. At the time of the study, a farmer in the region earned an average of C $\$ 100$ a day (approximately US $\$ 3.77$ ). Once the starting point was determined, the remaining payoff options were determined following recommendations from Yesuf and Bluffstone [40]. The constant relative risk aversion utility function, $U(x)=\frac{x^{(1-r)}}{1-r}$, is used to measure the risk attitudes at which people should be indifferent between any two neighbouring lotteries (i.e., the utility of any lottery does not exceed the utility of getting the average monetary payoff of the lottery with certainty) and it is calculated as follows:

$$
U(100)=U(80)+U(150) \frac{100^{(1-r)}}{1-r}=\frac{1}{2} \times \frac{80^{(1-r)}}{1-r}+\frac{1}{2} \times \frac{150^{(1-r)}}{1-r}=0, r=2.96
$$

\subsection{Experiment Mechanics in the Field}

The experiments were conducted at the farmer's house, and played individually, preceding the survey and they lasted on average $30 \mathrm{~min}$ to complete. The results from the experiments were registered in tablets by the enumerators.

The experiment began by describing the framed context of the game, each of the six choice alternatives were described, and the enumerator explained how equal probabilities worked, before the farmer had to make a decision. Farmers were shown a laminated card containing a drawing of the risk lottery with its six possible alternatives (Figure 2). Farmers had to then choose one of the six different alternatives, each one containing two potential outcomes (the theoretical crop success or crop failure). The alternatives were: with alternative (1) the farmers simply received C $\$ 100$, in other words, the payoff was the same regardless of the outcome of the game; with alternative (2) the farmer could receive either $C \$ 80$ or $C \$ 150$, in other words by foregoing the first alternative, the farmer stood to lose $C \$ 20$ or to gain $C \$ 50$. The payoffs for alternatives three, four, and five, were $60 / 190,40 / 250$, and 20/300, respectively. Finally, by choosing the last alternative (6), the farmer ran the risk of not receiving money at all or of getting $C \$ 350$ (an amount associated with three and half days' worth of paid labour). Each choice is associated with a classification of a risk class, from risk averse in alternative (1) to risk 
neutral-to-preferring in alternative (6). The payoffs for each lottery choice were chosen so that the expected payoff and the variance of each lottery increases in clockwise order.



Figure 2. Example of laminated card with lottery alternatives.

To ensure comprehension of equal probability, each farmer was shown the contents of a bag, containing three orange balls and three white balls, and the enumerator explained how the likelihood of randomly drawing one colored ball was equal to a different colored ball. Before the farmer was asked to play the game, enumerators made sure that they understood these probabilities. Upon a farmer's choice of lottery (1 through 6 ), she randomly drew a ball from a bag held by the enumerator containing equal number of orange and white balls to determine the payoff for the activity. If the farmer drew an orange ball she received the low payoff, if she drew a white ball she received the high payoff. Payoffs from the experiment were paid in cash. On average, farmers were paid 150.25 Nicaraguan Córdobas (or 5.77 USD), an amount consisting of the average wages for 1.5 days of farm labour.

\section{Results}

In addition to results from the field experiments, in this section, I present a series of descriptive analyses that help us understand Nicaraguan coffee producers' perceptions about climate change and that help explain their capacities for climate change adaptation.

\subsection{Descriptive Analysis}

I begin this section by examining how all farmers in the sample have perceived changes in the climate of the region over the past five years. Overall, most farmers have perceived major changes in regional climate patterns; over $90 \%$ of households stated that they have seen changes in overall climate, and in temperatures specifically, over the past 10 years. A majority of farmers have also perceived temporal changes in the rainy season (74\%) as well as changes in the frequency of rainfall $(58 \%)$. Furthermore, $65 \%$ of households believe that the frequency of extreme events has changed over the past 10 years (Figure 3). The direction of these changes are estimated based on field observation during field visits and data collection; many farmers talked about recent droughts that had destroyed their maize and bean plantations (changes in the frequency of rainfall-fewer), and of early rains that caused their coffee trees to flower early (temporal changes in the rainy season). Farmers, due to the nature of their work, have their finger on the pulse of the weather and the land they work, and although they may not be aided by computerized tools and models to measure or estimate climatic events, their experience has taught them to recognize patterns and changes that affect the production of their crops. As seen with the households from this study, the vast majority of them have concluded that there have been changes in the climate, both in frequency and in the timing of the events. 




Figure 3. Perceptions about climate change; $\mathrm{HH}-$ Household.

Despite the high proportion of farmers reporting changes in weather patterns, a smaller proportion of them reported experiencing losses due to these changes over the past 5 years (Figure 4). Of the surveyed households, $75 \%, 43 \%$, and $17 \%$ reported experiencing pests, droughts, and floods (respectively) in their coffee fields. The most common overall response to these shocks was for producers to increase the number of household labour hours and to spend their savings to cope with losses. In addition, $40 \%$ of farmers who experienced pests switched to a different crop or to a new coffee variety and $29 \%$ of them changed their production practices to respond to the pest (e.g., applying more pesticides, pruning, or stumping coffee trees). Fifteen percent of households experiencing droughts had to decrease their food consumption. It is likely that these are households that in addition to coffee also grow subsistence crops, such as beans and maize, and saw a decline in their food crops due to droughts. Overall, farmers respond to pests at a higher rate than to droughts and floods, possibly due to the institutional response and support in the area to the recent leaf rust outbreak.



Figure 4. Responses to climate shocks. 
Cooperatives, through the support that they can provide in the provision of inputs, trainings, and other extension services, can play an important role in helping farmers in their adaptation efforts. The sample in this study is evenly split between cooperative members and non-members, with $45.5 \%$ of farmers belonging to a coffee cooperative. Of these cooperative members, however, $74 \%$ expressed being dissatisfied or very dissatisfied with their cooperatives, and only $26 \%$ of them stated that they were satisfied or very satisfied with their cooperatives. Farmers in this sample belonged to a wide range of cooperative groups, including organic, Fair Trade, and other regional based groups. During data collection, farmers shared anecdotes reflecting the lack of support from cooperatives and an overall sense that these relationships were more extractive than supportive. One producer told us that she had never received premiums that were promised for her coffee, and, along with other farmers, implied corruption within the cooperatives' leadership. One farmer mentioned that he has seen other farmers dump the waste water from processing the cherry into streams, with no consequences and no monitoring from the cooperative support staff. Although anecdotal, these stories help us understand producers' discontent with their cooperatives.

Moving beyond farmer perceptions and preferences, I focus on an indicator of climate change vulnerability that allows us to examine the degree to which respondents in this sample are currently living in areas that are at risk of suffering losses due to climate change impacts. Using elevation of farm as an indicator of vulnerability to climate change, I find that by $2020,16 \%, 47 \%$, and $37 \%$ of households located in Matagalpa will experience little, medium, and high impacts from climate change, respectively. The situation becomes even direr by 2050, by which time everyone in this sample will be located in regions vulnerable to climate change impacts, with the majority of them (62\%) experiencing high impacts.

In addition to vulnerability to climate change, data from this study indicates that $88.6 \%$ of households in the sample are severely food insecure, and have had to lower the amount of food consumed and also compromise the quality of the food they consume at home.

To analyze differences in outcomes between men and women, I standardized yield and income in the sample by the amount of land operated by the household. I find that female-headed households hold significantly less land (1.66 ha vs. $2.77 \mathrm{ha}$ ), which produces less coffee (10.02 quintales vs. 13.03 quintales), in turn generating less income (568.9 USD vs. 952.3 USD) than male-headed households. Additionally, women are significantly more food insecure than men. Of the survey respondents, $96 \%$ of female-headed households suffered from food insecurity versus $85 \%$ of male-headed households (Table 2).

Table 2. Gender Differences.

\begin{tabular}{cccc}
\hline & Male & Female & $p$-Value \\
\hline Average Area Under Coffee Production (ha) & 2.77 & 1.66 & 0.002 \\
Average Yield per Hectare of Coffee (kg) & 599.38 & 460.92 & 0.086 \\
Average Income Per Hectare of Coffee & 952.30 & 568.90 & 0.001 \\
Percentage of Households Suffering from Food Insecurity & $85 \%$ & $96 \%$ & 0.019 \\
\hline
\end{tabular}

\subsection{Experiment Results}

I use an ordered probit model to examine the determinants of farmer risk preference. The econometric specification for this model is presented below:

$$
\begin{aligned}
& \text { Risk }_{i}=\beta_{1} \text { HHSize }_{i} \quad+\beta_{2} \text { Sex }_{i}+\beta_{3} \text { Education }_{i}+\beta_{4} \text { Age } i+\beta_{5} \text { Income }_{i} \\
& +\beta_{6} \text { Income }_{i}^{2}+\beta_{7} \text { Area }_{i}+\beta_{8} \text { Experience }_{i} \\
& +\beta_{9} \text { Food Insecurity } 1_{i}+\beta_{10} \text { Food Insecurity } 2_{i}+\varepsilon_{i}
\end{aligned}
$$

Risk $k_{i}$ represents individual i's choice from 1 to 6 in the risk activity, where a higher value represents higher riskiness. $\beta_{1}$ represents the estimated coefficient for each regressor and $\varepsilon_{i}$ is stochastic component 
of this model. The model includes household demographics, farm characteristics, and a dummy variable indicating level of food insecurity experienced by households.

I begin the analysis of risk preferences by looking at the distribution of risk choices among the different variables in the model (Table 3). On average, larger households, older people, and farmers with more land are more likely to choose the less risky option, while more educated households and men tend to choose the riskier options. There is curvilinear trend of risk choices for different income levels, with those who are most and least risk-adverse also having the highest average income levels. It is interesting to note that households with more land (overall) tend to be more risk averse, on average, than those with less income and land.

Table 3. Distribution of Risk Choices.

\begin{tabular}{|c|c|c|c|c|c|c|}
\hline & \multicolumn{6}{|c|}{ Low Risk $\leftarrow-\cdots \rightarrow$ High Risk } \\
\hline & Choice 1 & Choice 2 & Choice 3 & Choice 4 & Choice 5 & Choice 6 \\
\hline Average HH Size & 6.2 & 5.1 & 6.2 & 5.4 & 4.4 & 5.0 \\
\hline Male (\%) & 57 & 75 & 68 & 56 & 63 & 80 \\
\hline Average Years of Education & 3.3 & 4.2 & 3.6 & 4.5 & 6.4 & 5.0 \\
\hline Average Age & 51.8 & 43.9 & 47.5 & 47.9 & 47.4 & 47.6 \\
\hline Average Total Income (USD) & 18,807 & 5721 & 3162 & 6896 & 6925 & 10,371 \\
\hline Average Total Area (ha) & 11.4 & 4.6 & 4.6 & 9.1 & 6.4 & 7.6 \\
\hline Average Coffee Experience (years) & 13.5 & 14.0 & 20.3 & 17.2 & 18.6 & 19.3 \\
\hline
\end{tabular}

When the lotteries are numbered in increasing riskiness from one to six, clockwise, the average choice in the risk game is 3.1 which puts the average choice of participants close to the $60 \mid 90$ gamble.

A quick look at the distribution of choices and food insecurity helps us understand how these households made their choice selections (Figure 5). Households with no food insecurity tend to make riskier choices, while households suffering from severe food insecurity consistently select the less risky options. Not a single household in the sample that belonged to the highest food insecurity category chose option 6 in the game.



Figure 5. Game choices by households with food insecurity.

Table 4 presents the results from the econometric model. From this model, a number of important findings can be seen: men, higher educated respondents, and younger respondents tend to have a higher likelihood of selecting the riskier options. Household heads with more land, however, have 
a higher likelihood of choosing the less risky option, although the differences are not statistically significant. In addition, larger households with more members are significantly more likely to "play it safe" in their choices. With each additional household member, the likelihood of selecting the riskier $\mathrm{C}$ $\$ 0 \mid \mathrm{C} \$ 350$ choice decreases by $14.7 \%$.

Table 4. Results from Ordered Probit Model for Risk Aversion.

\begin{tabular}{ccc}
\hline & Coefficient & Std. Error \\
\hline HH Size & $-0.258^{* * *}$ & 0.106 \\
Male & -0.069 & 0.444 \\
Education & 0.027 & 0.064 \\
Age & -0.017 & 0.017 \\
Income & $0.005^{*}$ & 0.003 \\
Income squared & $-4.28 \times 10^{-6 * *}$ & $1.92 \times 10^{-6}$ \\
Total Area & -0.027 & 0.020 \\
Coffee Experience & $0.036^{*}$ & 0.022 \\
Moderate Food Insecurity & $-2.436^{* * *}$ & 0.765 \\
Severe Food Insecurity & $-2.237^{* * *}$ & 0.838 \\
\hline Log Likelihood & -127.56 & \\
Chi-square & 28.50 & \\
$n$ & 82 &
\end{tabular}

As household income increases, so does the likelihood of the selection of riskier options in the game. The significance of the square term in the model points toward a curvilinear relationship between risk and income. In other words, although there is a higher likelihood of selecting a riskier option for higher income households, this positive trend occurs at a decreasing rate. Finally, severely food insecure and moderately food insecure households are $158 \%$ and $127 \%$ less likely to select a risky choice, respectively, than households that do not suffer from food insecurity.

\section{Discussion}

Our findings show that farmers are experiencing climate change-related events and that they recognize that there is a new normal in the environmental patterns that they have relied on to produce coffee. Most of their responses to these changes have been reactive, responses that help them cope with the events but do not constitute adaptation as defined by Adger et al. [6]. They have increased the amount of household labour, spent their savings, decreased their food consumption, and fell into debt, all of which are responses that could potentially leave them more vulnerable to future events. Some responses, however, indicate that some farmers are responding more proactively to the changes that they are experiencing, like changing their coffee varieties to new more resistant ones, and changing their growing practices, which are responses that will be more likely to help them adapt to the changing environmental conditions affecting coffee production. Proactive responses that lead to adaptation are not always easy to engage in, not only because there is uncertainty about how successful they will be but also because farmers must rely on the knowledge and the institutional support to implement these measures.

Despite studies that have found that poorer agrarian households tend to be more risk-averse than higher income households [38,54-56], many other studies have found the opposite [57,58]. Given that there is still no consensus about the relationship between risk aversion and poverty [53], the results from this study can contribute to this literature. In agreement with several previous studies [38,54-56], the present research shows that poor households tend to be more risk-averse than non-poor households.

The analysis of risk attitudes among food insecure households can, on the one hand, be encouraging because we see that that households that are already vulnerable are less likely to risk exacerbating their vulnerabilities by engaging in risky behaviour. On the other hand, this risk aversion could mean 
that vulnerable households will be less likely to engage in activities that they may deem risky but that could potentially have great benefits to their wellbeing, for example, the adoption of new technologies or practices that could help them become more resilient to climate and market shocks. An important contribution from this study is the finding that a household's capacity to provide nutritious food without uncertainty about future food access and availability helps to determine whether the household may be more or less risk-averse.

We find that larger households tend to be more risk-adverse, the constraints that these households face might explain this, for example, larger households may have a higher proportion of dependents (children and elderly) and are not, therefore, willing to take the risks that they would take otherwise. Any risks that they take could affect a higher proportion of vulnerable household members, as shown by Yesuf and Bluffstone [40] in Ethiopia.

Not many studies that measure the effect of food insecurity on risk attitudes have been found, but these results are consistent with similar studies that have accounted for food insecurity and hunger and their relationship with risk $[61,65]$.

\section{Conclusions}

In this paper, I examined the perceptions, capacities, and attitudes of coffee producers towards climate change and their adaptation to its impacts. The future of coffee production in Nicaragua is uncertain, and the vulnerability of poor and food insecure coffee producing households is compounded by a changing climate which may result in medium to severe impacts to the region. The suitability of their coffee farms to the changing environment will continue to decline, threatening their livelihoods and food security even further.

Farmers are already experiencing droughts, floods, and pests and some have had to respond by increasing the number of work hours that they dedicate to their fields. This additional physical labour (mostly) can result in potential health loss due to accidents, longer exposure time to chemical inputs, and lack of proper nutrition to support their increased physical exertion. Furthermore, some have already responded by decreasing their food consumption as a coping mechanism, a response that further jeopardizes their health and productive capacity.

This danger is especially acute for women. Women are significantly more food insecure than men; they own less land, produce less, and have lower income than their male counterparts. Policies designed to promote adaptation behaviour among farmers in the region must account for these differences by introducing interventions that directly address the barriers (cultural and economic) that women face. Further research is needed to examine specifically how gender differences affect adaptive capacity and adaptation, and to guide the development of strategies that will be responsive to these differences.

Researchers studying the risk preferences of poor rural households are not all in agreement, and the literature on this issue is still inconclusive. Furthermore, there are relatively few studies that explores risk aversion among households that are already highly vulnerable, especially households who are suffering from food insecurity. These results provide an important contribution to this debate. While holding income level constant, I find that households that are severely and moderately food insecure are significantly less likely to make riskier choices than are those not suffering from food insecurity.

The implications of these results should not be taken lightly. Climate shocks can destroy crops, livestock, and other household assets; for households in chronic poverty, conventional risk management strategies simply may not be enough. The challenge lies in the development and provision of services, institutions, and interventions that enable the accumulation of productive assets and the adoption of improved agricultural production technologies that will be instrumental to building the capacity of households in their struggle to adapt to climate change.

Interventions that intend to reduce vulnerability to shocks should consider how households that are severely food insecure, perhaps already trapped in poverty, will respond to possible adaptation pathways and the inherent risks associated with them. An important recommendation for programs 
focused on helping the most vulnerable populations to adopt technologies and practices that can help with climate change emerges from this study. These programs must first address issues of food insecurity among poor households; by doing so, there is a non-negative likelihood that the targeted farmers will be more open to taking the risks associated with the adoption of new practices and technologies.

While the results reported from this analysis help us to assess how risk and food security combine to affect potential farmer decisions concerning the adoption of climate change friendly practices, the following caveats must be acknowledged: first, the overall sample, and the number of participants in the experimental games is small; information from only 82 farmers is used in the econometric analysis. Future research on a larger sample of participants will help to validate the results of this study. Second, food security data on the study households was collected a year earlier than other data presented in this analysis. This lag does not capture any changes in food-security within the lag. In other words, households identified as food insecure in this study may not have been food insecure at the time of the risk activity, thus potentially diluting the strength of the coefficients reported and the relationships they represent. Third, given that recall periods about specific events are not always accurate, especially for longer periods of time, a triangulation of recall data with geocoded climate data could help determine the accuracy of responses, as well as give us information of differences in perceptions of events and actual events. Finally, although these experiments attempt to emulate real-life behaviour and measure how farmers respond to risks, farmers may not feel the same way about taking a relatively small risk presented to them by the enumerators of the study as they would about a decision that could lock them into poverty in real life, or help them rise from poverty. To further explore the relationships revealed in this study between risk, food security, and climate change adaptation, I see the need for a more qualitative approach, one that will provide deeper insight into how coffee producers evaluate the potential risks and rewards of adopting alternative practices and how, in turn, cooperatives and other institutions can work more effectively to support them in their decisions.

Funding: This research was funded by United States Agency for International Development: RC104408.

Acknowledgments: I would like to acknowledge the financial support provided by the Borlaug Fellows in Global Food Security at Purdue University, as well as the support provided by the International Center for Tropical Agriculture (CIAT) in Nicaragua. Finally, I would like to thank the field enumerators who made data collection possible, as well the coffee producers who took time to participate in the survey.

Conflicts of Interest: The author declares no conflict of interest.

\section{References}

1. Yulia, Y. The governance of Scientific Assessment in the Context of the Intergovernmental Panel on Climate Change: Lessons for International Cooperation in Science, Technology and Innovation; Discussion Paper, No. 7/2014; Deutsches Institut für Entwicklungspolitik (DIE): Bonn, Germany, 2014.

2. Laderach, P.; Lundy, M.; Jarvis, A.; Ramírez, J.; Portilla, E.P.; Schepp, K.; Eitzinger, A. Predicted Impact of Climate Change on Coffee Supply Chains. In Climate Change Management; Springer: Berlin/Heidelberg, Germany, 2010; pp. 703-723.

3. Haggar, J.; Medina, B.; Aguilar, R.M.; Muñoz, C. Land Use Change on Coffee Farms in Southern Guatemala and its Environmental Consequences. Environ. Manag. 2013, 51, 811-823. [CrossRef] [PubMed]

4. Ellis, F. Rural Livelihoods and Diversity in Developing Countries; Oxford University Press: Oxford, UK, 2000.

5. Intergovernmental Panel on Climate Change. Climate Change 2007: Impacts, Adaptation and Vulnerability; Cambridge University Press: Cambridge, MA, USA, 2007.

6. Adger, W.N.; Arnell, N.W.; Tompkins, E.L. Successful adaptation to climate change across scales. Glob. Environ. Chang. 2005, 15, 77-86. [CrossRef]

7. Quiroga, S.; Suárez, C.; Solís, J.D.; Martinez-Juarez, P. Framing vulnerability and coffee farmers' behaviour in the context of climate change adaptation in Nicaragua. World Dev. 2020, 126, 104733. [CrossRef]

8. Hazell, P.; Poulton, C.; Wiggins, S.; Dorward, A. The Future of Small Farms: Trajectories and Policy Priorities. World Dev. 2010, 38, 1349-1361. [CrossRef] 
9. Bradshaw, B.; Dolan, H.; Smit, B. Farm-Level Adaptation to Climatic Variability and Change: Crop Diversification in the Canadian Prairies. Clim. Chang. 2004, 67, 119-141. [CrossRef]

10. Head, L.; Atchison, J.; Gates, A.; Muir, P. A fine-grained study of the experience of drought, risk and climate change among Australian wheat farming households. Ann. Assoc. Am. Geogr. 2011, 101, 1089-1108. [CrossRef]

11. Zaval, L.; Cornwell, J.F. Cognitive biases, non-rational judgments, and public perceptions of climate change. In Oxford Research Encyclopedia of Climate Science; Oxford University Press: Oxford, UK, 2016.

12. Abebaw, D.; Haile, M.G. The impact of cooperatives on agricultural technology adoption: Empirical evidence from Ethiopia. Food Policy 2013, 38, 82-91. [CrossRef]

13. Bro, A.S.; Clay, D.C.; Ortega, D.L.; Lopez, M.C. Determinants of adoption of sustainable production practices among smallholder coffee producers in Nicaragua. Environ. Dev. Sustain. 2019, 21, 895-915. [CrossRef]

14. Bacon, C.M. A Spot of Coffee in Crisis. Lat. Am. Perspect. 2010, 37, 50-71. [CrossRef]

15. Bacon, C.M.; Sundstrom, W.A.; Stewart, I.T.; Beezer, D. Vulnerability to Cumulative Hazards: Coping with the Coffee Leaf Rust Outbreak, Drought, and Food Insecurity in Nicaragua. World Dev. 2017, 93, 136-152. [CrossRef]

16. Tompkins, E.L.; Adger, W.N. Does Adaptive Management of Natural Resources Enhance Resilience to Climate Change? Ecol. Soc. 2004, 9. [CrossRef]

17. De Sousa, K.; Van Zonneveld, M.; Holmgren, M.; Kindt, R.; Ordoñez, J.C. The future of coffee and cocoa agroforestry in a warmer Mesoamerica. Sci. Rep. 2019, 9, 1-9. [CrossRef] [PubMed]

18. Rahn, E.; Vaast, P.; Laderach, P.; Van Asten, P.; Jassogne, L.; Ghazoul, J. Exploring adaptation strategies of coffee production to climate change using a process-based model. Ecol. Model. 2018, 371, 76-89. [CrossRef]

19. Pendergrast, M. Uncommon Grounds: The History of Coffee and How It Transformed Our World; Basic Books: New York, NY, USA, 2010.

20. Ponte, S. The 'Latte Revolution'? Regulation, Markets and Consumption in the Global Coffee Chain. World Dev. 2002, 30, 1099-1122. [CrossRef]

21. Moat, J.; Gole, T.W.; Davis, A.P. Least concern to endangered: Applying climate change projections profoundly influences the extinction risk assessment for wild Arabica coffee. Glob. Chang. Boil. 2019, 25, 390-403. [CrossRef]

22. Laderach, P.; Ramirez-Villegas, J.; Navarro-Racines, C.; Zelaya, C.; Martinez-Valle, A.; Jarvis, A. Climate change adaptation of coffee production in space and time. Clim. Chang. 2016, 141, 47-62. [CrossRef]

23. Conde, C.; Vinocur, M.; Gay, C.; Seiler, R.; Estrada, F. Climatic threat spaces in Mexico and Argentina. In Climate Change and Vulnerability; Leary, N., Conde, C., Kulkarni, J., Nyong, P.J., Eds.; Earthscan: London, UK, 2007; pp. 279-306.

24. McLeman, R.A. Climate and Human Migration: Past Experiences, Future Challenges; Cambridge University Press: Cambridge, MA, USA, 2014.

25. Bunn, C. Achieving Climate-Smart Coffee in East Africa; International Center for Tropical Agriculture (CIAT): Washington, DC, USA, 2019.

26. Jaramillo, J.; Muchugu, E.; Vega, F.E.; Davis, A.; Borgemeister, C.; Chabi-Olaye, A. Some Like It Hot: The Influence and Implications of Climate Change on Coffee Berry Borer (Hypothenemus hampei) and Coffee Production in East Africa. PLoS ONE 2011, 6, e24528. [CrossRef]

27. Moat, J.; Williams, J.; Baena, S.; Wilkinson, T.; Gole, T.W.; Challa, Z.K.; Demissew, S.; Davis, A.P. Resilience potential of the Ethiopian coffee sector under climate change. Nat. Plants 2017, 3, 17081. [CrossRef]

28. Meza, L.E.R. Adaptive capacity of small-scale coffee farmers to climate change impacts in the Soconusco region of Chiapas, Mexico. Clim. Dev. 2014, 7, 100-109. [CrossRef]

29. Baca, M.; Laderach, P.; Haggar, J.; Schroth, G.; Ovalle, O. An Integrated Framework for Assessing Vulnerability to Climate Change and Developing Adaptation Strategies for Coffee Growing Families in Mesoamerica. PLOS ONE 2014, 9, e88463. [CrossRef]

30. Tucker, C.M.; Eakin, H.; Castellanos, E.J. Perceptions of risk and adaptation: Coffee producers, market shocks, and extreme weather in Central America and Mexico. Glob. Environ. Chang. 2010, 20, 23-32. [CrossRef]

31. World Bank; International Finance Corporation. Nicaragua Paving the Way to Faster Growth and Inclusion: Systematic Country Diagnostic. Available online: https://openknowledge.worldbank.org/handle/10986/27560 (accessed on 10 March 2020). 
32. Valkila, J.; Nygren, A. Impacts of Fair Trade certification on coffee farmers, cooperatives, and laborers in Nicaragua. Agric. Hum. Values 2009, 27, 321-333. [CrossRef]

33. Perfecto, I.; Vandermeer, J. Coffee Agroecology: A New Approach to Understanding Agricultural Biodiversity, Ecosystem Services and Sustainable Development; Routledge: London, UK, 2015.

34. Philpott, S.M.; Dietsch, T. Coffee and Conservation: A Global Context and the Value of Farmer Involvement. Conserv. Boil. 2003, 17, 1844-1846. [CrossRef]

35. Holt-Giménez, E. Measuring farmers' agroecological resistance after Hurricane Mitch in Nicaragua: A case study in participatory, sustainable land management impact monitoring. Agric. Ecosyst. Environ. 2002, 93, 87-105. [CrossRef]

36. Mann, M.E.; Emanuel, K.A. Atlantic hurricane trends linked to climate change. Eos Trans. Am. Geophys. Union 2006, 87, 233. [CrossRef]

37. Bro, A.S.; Ortega, D.L.; Clay, D.C.; Richardson, R.B. Understanding individuals' incentives for climate change adaptation in Nicaragua's coffee sector. Clim. Dev. 2020, 12, 332-342. [CrossRef]

38. Tanaka, T.; Camerer, C.F.; Nguyen, Q. Risk and Time Preferences: Linking Experimental and Household Survey Data from Vietnam. Am. Econ. Rev. 2010, 100, 557-571. [CrossRef]

39. Carter, M.R.; Barrett, C.B. The economics of poverty traps and persistent poverty: An asset-based approach. J. Dev. Stud. 2006, 42, 178-199. [CrossRef]

40. Yesuf, M.; Bluffstone, R.A. Poverty, Risk Aversion, and Path Dependence in Low-Income Countries: Experimental Evidence from Ethiopia. Am. J. Agric. Econ. 2009, 91, 1022-1037. [CrossRef]

41. Fisher, M.; Abate, T.; Lunduka, R.W.; Asnake, W.; Alemayehu, Y.; Madulu, R.B. Drought tolerant maize for farmer adaptation to drought in sub-Saharan Africa: Determinants of adoption in eastern and southern Africa. Clim. Chang. 2015, 133, 283-299. [CrossRef]

42. Wossen, T.; Berger, T.; Di Falco, S. Social capital, risk preference and adoption of improved farm land management practices in Ethiopia. Agric. Econ. 2015, 46, 81-97. [CrossRef]

43. Duflo, E.M.; Kremer, M.; Robinson, J. Nudging Farmers to Use Fertilizer: Theory and Experimental Evidence from Kenya. Am. Econ. Rev. 2011, 101, 2350-2390. [CrossRef]

44. Marra, M.; Pannell, D.; Ghadim, A.A. The economics of risk, uncertainty and learning in the adoption of new agricultural technologies: Where are we on the learning curve? Agric. Syst. 2003, 75, 215-234. [CrossRef]

45. Feder, G.; Just, R.E.; Zilberman, D. Adoption of Agricultural Innovations in Developing Countries: A Survey. Econ. Dev. Cult. Chang. 1985, 33, 255-298. [CrossRef]

46. Ayenew, H.; Sauer, J.; Abate-Kassa, G. On smallholder farmers' exposure to risk and adaptation mechanisms: Panel data evidence from Ethiopia. In Proceedings of the 89th Annual Conference of the Agricultural Economics Society, Coventry, UK, 13-15 April 2015.

47. Lawin, K.G.; Tamini, L.D. Risk preferences and crop diversification amongst smallholder farmers in Burkina Faso. In Proceedings of the Annual Meeting of Canadian Agricultural Economics Society, Montreal, QC, Canada, 18-21 June 2017.

48. Engle-Warnick, J.; Escobal, J.; Laszlo, S. Ambiguity Aversion as a Predictor of Technology Choice: Experimental Evidence from Peru. SSRN Electron. J. 2007. [CrossRef]

49. Cardenas, J.C.; Carpenter, J. Risk attitudes and economic well-being in Latin America. J. Dev. Econ. 2013, 103, 52-61. [CrossRef]

50. Partey, S.T.; Dakorah, A.D.; Zougmore, R.B.; Ouedraogo, M.; Nyasimi, M.; Nikoi, G.K.; Huyer, S. Gender and climate risk management: Evidence of climate information use in Ghana. Clim. Chang. 2018, 158, 61-75. [CrossRef]

51. Ruben, R.; Zuniga, G. How standards compete: Comparative impact of coffee certification schemes in Northern Nicaragua. Supply Chain Manag. Int. J. 2011, 16, 98-109. [CrossRef]

52. Thaler, R.H. Irving Fisher: Modern Behavioural Economist. Am. Econ. Rev. 1997, 87, 439-441.

53. Cardenas, J.C.; Carpenter, J. Behavioural Development Economics: Lessons from Field Labs in the Developing World. J. Dev. Stud. 2008, 44, 311-338. [CrossRef]

54. Hartog, J.; Jonker, N.; Ferrer-I-Carbonell, A. Linking Measured Risk Aversion to Individual Characteristics. Kyklos 2002, 55, 3-26. [CrossRef]

55. Donkers, B.; Melenberg, B.; Van Soest, A. Estimating Risk Attitudes using Lotteries: A Large Sample Approach. J. Risk Uncertain. 2001, 22, 165-195. [CrossRef] 
56. Moscardi, E.; De Janvry, A. Attitudes Toward Risk Among Peasants: An Econometric Approach. Am. J. Agric. Econ. 1977, 59, 710-716. [CrossRef]

57. Bosch-Domènech, A.; Silvestre, J. Do the Wealthy Risk More Money? An Experimental Comparison Institutions, Equilibria and Efficiency; Springer: New York, NY, USA, 2006; pp. 95-116.

58. Henrich, J.; McElreath, R. Are Peasants Risk-Averse Decision Makers? Curr. Anthr. 2002, 43, $172-181$. [CrossRef]

59. Haushofer, J.; Fehr, E. On the psychology of poverty. Science 2014, 344, 862-867. [CrossRef] [PubMed]

60. Agarwal, B. Conceptualising environmental collective action: Why gender matters. Camb. J. Econ. 2000, 24, 283-310. [CrossRef]

61. Levy, D.J.; Thavikulwat, A.C.; Glimcher, P.W. State Dependent Valuation: The Effect of Deprivation on Risk Preferences. PLoS ONE 2013, 8, e53978. [CrossRef]

62. Jimenez-Soto, E. The political ecology of shaded coffee plantations: Conservation narratives and the everyday-lived-experience of farmworkers. J. Peasant. Stud. 2020, 1-20. [CrossRef]

63. Binswanger, H.P. Attitudes toward risk: Experimental measurement in rural India. Am. J. Agric. Econ. 1980, 62, 395-407. [CrossRef]

64. Holt, C.A.; Laury, S.K. Risk Aversion and Incentive Effects. Am. Econ. Rev. 2002, 92, 1644-1655. [CrossRef]

65. Onyemauwa, C.S.; Orebiyi, J.S.; Onyeagocha, S.U.O.; Ehirim, N.C.; Nwosu, F.O.; NG, B.C. Risk aversion among farmers of the national program for food security in Imo State Southeast Nigeria. J. Econ. Sustain. Dev. 2013, 4, 131-137.

(C) 2020 by the author. Licensee MDPI, Basel, Switzerland. This article is an open access article distributed under the terms and conditions of the Creative Commons Attribution (CC BY) license (http://creativecommons.org/licenses/by/4.0/). 